\title{
Article
}

\section{Subjective experiences of compulsory treatment from a qualitative study of early implementation of the Mental Health (Care and Treatment)(Scotland) Act 2003}

Ridley, Julie and Hunter, Susan

Available at http://clok.uclan.ac.uk/6671/

Ridley, Julie ORCID: 0000-0002-0879-308X and Hunter, Susan (2013)

Subjective experiences of compulsory treatment from a qualitative study of early implementation of the Mental Health (Care and Treatment)(Scotland) Act 2003. Health and Social Care in the Community, 21 (5). pp. 509-518. ISSN 0966-0410

It is advisable to refer to the publisher's version if you intend to cite from the work. http://dx.doi.org/10.1111/hsc.12041

For more information about UCLan's research in this area go to

http://www.uclan.ac.uk/researchgroups/ and search for < name of research Group>.

For information about Research generally at UCLan please go to http://www.uclan.ac.uk/research/

All outputs in CLoK are protected by Intellectual Property Rights law, including Copyright law. Copyright, IPR and Moral Rights for the works on this site are retained by the individual authors and/or other copyright owners. Terms and conditions for use of this material are defined in the policies page. 


\section{Subjective experiences of compulsory treatment from a qualitative study of early implementation of the Mental Health (Care \& Treatment) (Scotland) Act 2003}

\begin{tabular}{|r|l|}
\hline Journal: & Health \& Social Care in the Community \\
\hline Manuscript ID: & HSCC-OA-12-0115.R2 \\
\hline Manuscript Type: & Original Article \\
\hline Keywords: & $\begin{array}{l}\text { Adult Mental Health Care, User's Views, Cohort Studies, Community } \\
\text { Treatment, Qualitative Research, Mental Health Act }\end{array}$ \\
\hline \multicolumn{2}{|l}{} \\
\hline
\end{tabular}




\section{Abstract}

Compulsory psychiatric treatment is highly contested, and little research has focused specifically on direct experiences. The Mental Health (Care \& Treatment) (Scotland) Act, 2003 introduced new roles and provisions including community treatment orders, and was designed to increase participation, ensure treatment was beneficial and was the 'least restrictive' alternative. This article draws on findings from semistructured interviews with 49 individuals who had experienced compulsion under this new legislation during 2007-08, that were part of a broader cohort study. Interviews with service users were conducted at two stages with $80 \%$ agreeing to be interviewed twice. The sample included people on a variety of compulsory orders from four Health Board areas, some of whom had been detained for the first time, while others reported 'revolving door' experiences. Peer researchers who were mental health service users carried out the interviews with professional researchers. The findings suggest that legislation had a limited impact on participation in the process of compulsion. Consensus was that although service users felt there was increased opportunity for their voices to be heard, this was not matched by having increased influence over professional decision-making, especially in relation to drug treatments. According to people's direct experiences, the passing of the legislation in itself had done little to change the dominant psychiatric paradigm. While providing a foundation for improving the process of compulsion, the findings suggest that as well as legislative reform, fundamental shifts in practice are needed both in terms of the nature of therapeutic relationships, and in embracing more holistic and recovery perspectives. 
Keywords: Adult Mental Health Care, User's Views, Cohort Studies, Community Treatment, Qualitative Research, Mental Health Act

\section{What is known about this topic}

- In recent years, the use of compulsory measures in the UK has increased, particularly the use of community-based orders introduced under the Mental Health (Care \& Treatment) (Scotland) Act 2003, and the Mental Health Act 2007.

- The subjective experience of compulsion paints a complex, multi-layered picture - negative and unhelpful experiences contrast with compulsion as supportive and helpful.

- Previous studies show wide variation in service users' views of compulsion with between $39 \%$ and $86 \%$ at different points feeling that compulsory admission was necessary in their situation.

\section{What this paper adds}

- A qualitative approach enables more meaningful exploration of service users' feelings about compulsion including expressing ambivalent views.

- Signs of increased participation generally as a result of the Mental Health (Care \& Treatment) (Scotland) Act 2003 (MHCT Act), did not necessarily equate with increased involvement in decision-making about care and treatment, or a shift towards concordant treatment approaches.

- Service users call for a shift in the type and quality of professionals' relationship with them, and for there to be a variety of treatment options. 


\section{Introduction}

Whilst still in force across the world, compulsory treatment remains highly contested, especially for supervision and enforced treatment in community settings (Szasz, 1974; Canvin et al, 2002; Pilgrim 2007). Compulsory admissions in the UK overall have been increasing, especially those people under community-based orders. Between the years $2008-9$ and $2009-10$, nearly $40 \%$ of all inpatients in England and Wales were compulsory admissions (Gould, 2011). During this same period in Scotland, $11 \%$ of psychiatric inpatient stays, increasing to $16 \%$ by 2011 , were compulsory admissions (ISD Scotland, 2011). In the context of cuts in inpatient beds over recent years, this means wards with increasing numbers of those with the most serious conditions (Fowler, 2011). New legislation - the Mental Health (Care \& Treatment) (Scotland) Act 2003 (MHCT Act) - implemented in 2005, explicitly aimed to 'modernise' practices, introducing legally enforceable community compulsory treatment. While in Scotland this was perceived as a positive innovation (Cosh, 2009), elsewhere such measures are not only regarded as a serious civil rights issue, but as potentially imposing grave damage from long term psychiatric drug use (Fowler, 2011).

This new Act was drafted following a root and branch review and based upon extensive consultation (Millan, 2001). This highlighted broad consensus regarding the improvements sought (Rosengard \& Laing, 2001; Grant, 2004). Service users reported negative experiences of detention, as well as feeling disempowered by hospital regimes, lack of structured activity, and poor physical conditions on some inpatient wards. Many recognised the case for compulsory detention and treatment but emphasised that consideration of human rights should be paramount. 
The MHCT Act was the most fundamental change for over 40 years, and was described as both 'visionary and revisionary' (Atkinson et al, 2005), It contained new provisions, underpinned by ten key principles:

- Compulsory measures enforced in the community

- Reciprocity as part of a principled framework

- New rights and safeguards - right to access independent advocacy, and to make an Advance Statement (Advanced Directives)

- A new Mental Health Tribunal (MHT) to consider the case for proposed compulsion

- New powers vested in the Mental Welfare Commission for Scotland (MWCS)

- New duties on health boards and local authorities in relation to social opportunities and well being

- Creation of special professional and supportive roles - Responsible Medical Officer or RMO (Psychiatrist), Approved Medical Practitioner or AMP (e.g. Psychiatrist or GP), Mental Health Officer or MHO (specialist Social Worker), and Named Person replacing 'next of kin'.

(Patrick, 2006)

Additionally, a right of appeal to the MHT was introduced for patients held under 'excessive security' at the State Hospital (secure hospital).

Research into the subjective experience of compulsion paints a somewhat complex, multi-layered picture. Service users report both negative and unhelpful experiences, 
as well as experiences of compulsion that have been supportive and helpful (Johansson \& Lundman, 2002; Jones et al, 2009). Qualitative studies, although sparse, have revealed wide variation in personal experience and viewpoint (Hughes et al, 2009) and recently researchers have called for research that seeks to understand compulsion from service user perspectives (Johansson \& Lundman, 2002; Lorem, 2008).

\section{Study purpose}

This cohort study (Ridley et al, 2009), was commissioned by Scottish Government as part of a national research programme to review developments in mental health law (Rushmer \& Hallam, 2004). Its broad aim was to evaluate implementation of the MHCT Act by exploring the experiences and perceptions of those directly affected by, and those professionals and advocates working with the Act. Of particular relevance to this article, the study explored the experiences and views of a sample of individuals who had been treated under the MHCT Act. A previous article focused on carers' viewpoints (Ridley, Hunter \& Rosengard, 2010).

\section{Methods}

In common with narrative-based studies (Scottish Recovery Network, 2007), we sought to place individuals' accounts at the centre of the research process while at the same time meeting pre-determined objectives. Semi-structured qualitative interviews were used to capture experiences of compulsion and to gain insight into how, if at all, the MHCT Act had impacted on this. This approach offered the 
flexibility needed to explore the complexity of individual experience and meaning (Temple, 1998).

Service users were sampled purposively from four research sites. The evaluation team included eight peer researchers, and interviews were conducted face-to-face by pairs of interviewers (a trained peer researcher working with a professional researcher). Interviews lasted from 30 minutes to over two hours, and took place in a variety of settings decided by participants. A few interviews were conducted with a supporter present: this was a family carer such as a spouse, an independent advocate, or in the case of asylum seekers or refugees, a language interpreter.

\section{Study Sample}

The study gathered data from unrelated samples of service users (49 individuals), carers (33 individuals), and professionals (38 health and social care professionals and advocates). Only the interviews with 49 service users are discussed in this article. This was a self selecting group of service users from a population with experience of being treated under the MHCT Act from one of four research sites. The sites were chosen to reflect urban, rural and mixed urban/rural NHS boards, and The State Hospital, Scotland's High Security Hospital.

\section{Sample recruitment}

Service users with experience of compulsory measures under the MHCT Act were invited to participate. The research commissioners insisted that the original target sample of 50 service users was to be obtained with the help of the Mental Welfare Commission for Scotland (MWCS), an independent body that monitors the MHCT 
Act. Letters and information sheets about the study were posted on our behalf during May 2007 to approximately 600 people. This elicited an initial response from 38 individuals. A second mailing resulted in a final sample of 49 service users (see Table 1 below). The MWCS sent a second mailing to anyone who had been added to its database in the intervening period.

Table 1 here

Consent

To establish capacity to consent to the research interview, service users were asked to nominate and provide contact details of a professional (e.g. psychiatrist, social worker, nurse) who they agreed could be contacted prior to an interview. Over three quarters of those who volunteered to participate were interviewed. A minority of nominated professionals (7) deemed that the person was too unwell to participate. Four were not interviewed for other reasons, including one for whom nursing home staff had completed the form without his knowledge. Another was a family member who subsequently participated as a carer. Replies from two others arrived some time after November 2007. A further three individuals withdrew prior to first interview.

\section{Data collection}

Information was gathered using semi-structured interview guides, consisting of open questions arranged around key topics and prompts. These reflected the commissioner's aim to obtain views on particular aspects of implementation while allowing participants the opportunity to determine the direction of the interview. 
Questions were drafted following an initial consultation with service users from two user organisations who discussed their experiences and knowledge of compulsion. A draft interview guide was further revised by peer researchers during training. Broad areas of questioning, adapted in response to each interviewee, were as follows:

Box 1 here

Service users recruited to the study were interviewed at two stages designed to be 12 months apart. Due to a protracted recruitment process, some stage 2 interviews had to be conducted at ten months. Of the 49 service users recruited, nearly $80 \%$ were interviewed again at stage 2.

Given the commissioner's interest in understanding how the new provisions and principles were being implemented, further questions were asked to determine people's experience of these. Few interviewees took up the offer of receiving transcripts. At stage 2 interviews, a summary was shared verbally with each participant to check for accuracy and validate our interpretation. Stage 2 interviews gathered additional information about some of the same domains, but also changes in individual circumstances, such as, whether or not they remained under a compulsory order or if this had been revoked, and if their views about compulsion had changed.

Box 2 here 
Service users were paid a nominal sum for their time and contribution for each interview.

\section{Peer researchers}

The research was carried out in partnership with mental health service users in line with the now well-established argument that better quality mental health research is produced when people are involved in the process (Rose, 2004; Turner \& Beresford, 2005; Szmuckler, 2009). A user organisation was part of the original partnership responding to the tender, and involved in recruiting and supporting paid peer researchers. The team comprised eight peer researchers and five professional researchers, one of whom had mental health service experience.

A number of other strategies were used to redress potential power imbalances. This included arranging interviews at a time and location that suited participants; adopting an open, semi-structured approach; making interviewees aware they could take a break, choose not to answer any question, or terminate the interview at any time without giving reasons. At the start of the interview, the peer researcher explained that he/she had experience as a mental health service user, and as far as practicable, the same pair of interviewers carried out second interviews to ensure familiarity.

\section{Ethics}

The study was approved by the University of Central Lancashire's Faculty of Health Research Ethics Committee and that of the State Hospital. Submission was made through the National Health Service (NHS) multi-centre research ethics process, 
including to Multicentre Research Ethics Committee (MREC) A for Scotland (considers research with people lacking capacity to consent). This committee decided the study was service evaluation and as such did not require NHS ethics approval.

\begin{abstract}
Analysis
With participants' consent, service user interviews were digitally recorded and transcribed in full. A pragmatic decision was taken to take notes in four interviews due to interviewee preference, communication difficulties or particular interview dynamics.
\end{abstract}

Interviews from stages 1 and 2 were analysed using standard methods of qualitative data analysis (Coffey \& Atkinson, 1996). The process of identifying key themes and a coding framework was driven by the research objectives, by emergent issues from the literature, and the team's interpretation. Initially, the whole team read through transcripts focussing on key topics, to arrive collectively at a coding framework, which was used by two researchers to code transcripts from both stages in Nvivo7. As Miles and Huberman (1994) argue, segmenting the data in this way helps set the stage for interpretative analysis. Following on from this, the whole team met to further interpret the coded data and begin the report writing process. Our interpretations were tested for validity with participants at second interviews, against the literature, within the team and with the Research Advisory Group. 


\section{Research Findings}

The 49 service user participants were not a homogenous group, nor were they necessarily representative of all experiences of the MHCT Act. Achieving diversity in the sample was a consideration, but the main criteria for inclusion were experience of compulsion under the MHCT Act; residing in one of the research sites; feeling able to revisit their experience of compulsion and having something they wanted to say about this. Key characteristics of the sample are summarised in Table 2.

Table 2 here

The sample reflected experience of the full range of compulsory measures (Table 3 below). Some interviewees were uncertain which treatment order, if any, they were under due to experiencing different compulsory measures in succession, or recent variance or suspension of a hospital-based Compulsory Treatment Order (CTO). Bearing this in mind, it is likely that the figure for community-based CTOs (35\%) may be inflated. The sample included some who had been formally detained for the first time, alongside others with experience of detention over many years.

Table 3 here

The findings are reported under six areas: feelings about compulsory treatment; participation under the MHCT Act; treatment under compulsion; experiences of detention; experiences of community compulsion; and lastly, improvements 
suggested by service users. Quotations have been anonymised, apart from indicating gender, the research site, and type of compulsory order.

Feelings about compulsion

Coercion was generally unwelcome. Nonetheless, over half $(52 \%)$ of the 39 people interviewed at Stage 2 reflected that compulsion had been the "right thing" for them at the time, a "necessary evil". Even so, a substantial minority $(42 \%)$ judged compulsion to have been "completely unnecessary". Interviewees drew attention to traumatic experiences of detention, often concluding that instead of contributing to their recovery, it had set them back:

"I think that I maybe needed support and help but I could have had it in my own environment in my own home rather than going into a hospital...It was a strange environment, a different environment, something that's... you know having to live with other people from all walks of life...just a bit strange." (Female, F, Short Term Order)

Longer-term participants from the State Hospital argued they should not be held under such high levels of security, even though in their opinion it had been appropriate initially. Subsequently, two of the five fought successful appeals and were moved, one to a medium secure ward, the other returned home.

At times, participants held conflicting views about the experience essentially viewing compulsory treatment negatively but with identifiable beneficial aspects :

"Well it could stop me from getting into any more trouble than I already got myself into. Somehow, it kept me stable...there would have been better ways of dealing with it, much better ways of dealing with it than hospitalisation." (Male, G, Hospital CTO) 


\section{Participation}

Increased participation was to be achieved through a number of provisions: MHTs replacing the Sheriff Court; encouragement to draw up Advance Statements; the Named Person replacing an assumption about nearest relatives; and increased access to independent advocacy, particularly for those facing MHT hearings.

Descriptions of first hand experiences of MHTs were mixed. One perspective contrasted them favourably with the 'old system' describing them as "relaxed", "fair", and "informal". Several reported a more participatory style and proceedings:

"Before it was in front of the Sheriff and...he was just swayed by ... what the gent told him sitting next to him and you were dealt with as the subject... and they discussed you over the top of you. The Tribunal, it is more interactive, you are getting more of a play...it's a step in the right direction." (Male, D\&G, Community CTO)

Conversely, others depicted adversarial settings. Unprompted, half of interviewees said the MHT decision had been a "foregone conclusion". Thus, although appearing to offer more opportunity for participation, decisions were perceived by service users to be weighted in clinicians' favour:

"I did get my tuppence worth, but it wasnae really worth anything". (Male, SH, Hospital CTO)

Professionals sometimes dominated proceedings and service users (as well as informal carers and advocates) given insufficient opportunity to speak. Some decided that the less they said the better, leaving all the talking to their lawyer or advocate for fear of saying something incriminating. Others felt that Panel members made little effort to understand their perspective or communication needs, including an individual with Aspergers Syndrome. 
Under the MHCT Act, individuals have a right to make an Advance Statement, and Tribunals are obliged to take these into account in their decision-making. Despite being two years into implementation, only half of interviewees had heard of them. Further, only seven of 39 people interviewed at Stage 2 had chosen to make one. A minority were completely satisfied with their treatment and could not envisage challenging clinicians' decisions. That an Advance Statement has to be witnessed by one of a prescribed set of professionals, and made when an individual is well, meant some interviewees felt they were redundant as they hoped not to be treated under the MHCT Act again.

Many were simply sceptical: although some could see potential benefits, the general consensus was that in practice such plans typically would be over-ruled:

"I've not made an Advance Statement because every time I try to they keep on blocking it... They've got the powers to overthrow it, so what's the point really?" (Male, F, Hospital CTO)

For many, Advance Statements did not offer the effective vehicle for participation envisaged; some gave examples of their statements being explicitly ignored:

"I was in the hospital and one of the doctors was wanting to put me back on the injection medication I had come off... and I said, 'I wrote down that I didn't want that again', and I got it anyway... When you're sectioned in hospital...you don't have much of a say what goes on...l said in my Advance Statement I didn't want C or D and they piled on the full dose..." (Male, G, Community CTO)

The Named Person role enables the person to decide who should have access to information and decision making meetings, moving away from an assumption that this should automatically fall to next of kin. Most participants had nominated a 
Named Person, commonly a close relative or friend. Views about its value differed: some were positive, others were undecided, and some felt that it made no difference. Notably by the time of the second interview, around a quarter had changed their Named Person to someone they considered more sympathetic to their viewpoint indicating that the role was beginning to provide some degree of choice for service users.

The MHCT Act provides a right to access independent advocacy. Service users generally knew about this right, and did make use of advocacy particularly in relation to MHTs. Independent advocates provided "comfort" and encouragement, helped people relax, and generally enabled them to participate more fully in MHTs. Service users were least positive about the effectiveness of advocacy when they had only been introduced to the advocate at the MHT. Further, some believed advocacy unnecessary when they had legal representation. Interestingly, lawyers interviewed for this study were in favour of independent advocacy, stressing the complementarity of roles.

\section{Compulsory treatment}

As part of the application for compulsion, the MHO prepares a care plan drawn up in collaboration with service users, carers and other relevant services. Those interviewed had only a vague idea of what a care plan is or should contain. Care plans equated with professionals' checklists to ensure treatment compliance:

"I do have a care plan but I dinnae ken what's in it...when I came out of hospital...there was an A4 sheet saying, 'continue taking your medication', and 'continue to see Dr B', and 'see your CPN'. So I presume that's what they mean by an aftercare plan?" (Female, F, Short Term Order) 
While the ethos of the MHCT Act and its underpinning principles emphasise a person centred and holistic approach, treatment under compulsion largely equated with drug therapies. Service users resented blanket treatment applied to diagnostic categories, particularly as these could be indeterminate or change:

"I've asked what the side effects are and nobody will tell me...The pills are upsetting my whole system, making me really ill. But no, it's 'take these pills because you've got this mental illness and everybody who's got this mental illness has to have this pill'..." (Female, G, Community CTO)

Despite reporting some benefits, accounts of drug therapies repeatedly highlighted over-medication and feeling "zombified". A catalogue of debilitating effects from powerful anti-psychotic drugs were listed, some of which had not been explained prior to treatment, and which had a negative impact on their quality of life:

"I'll get up in the morning, have my breakfast, take my pills, go to my bed an hour and half after taking the pills for a lie down...and I have a doze. Lunchtime, about an hour after lunchtime, have another doze, that takes me through to about three or four o'clock, go out to the shop, have tea, have another doze then finally go to bed at half past eleven at night...It's no much of a life really."

(Male, D\&G, Community CTO)

In only a few cases, had a change of medication been negotiated, reflecting some progress towards more concordant approaches favoured since the mid 1990s:

"She's a good psychiatrist, she's changed my medication a few times. I've told her that my medication that I was on wasnae working for me and she's changed it about until she got the right combination." (Male, S2, Short Term Order)

Non-medical aspects received far less attention despite the recovery thrust of the legislation and national service developments. There was little evidence of a strategic or consistent approach to promoting social and employment opportunities. Those who had successfully entered or re-entered employment had done so through 
their own motivation or because they had a good employer. Supported employment was rarely mentioned in care plans.

\section{Experience of detention}

Participants repeatedly commented that on hospital wards there was "plenty of time to do nothing". Recreational typically involved watching TV, playing music, going to the gym, playing pool or computer games, smoking and drinking coffee. Several highlighted the impact low staffing levels had on choice of, and access to activities. Although some Intensive Psychiatric Care Units (IPCUs) had well equipped recreation rooms, opening times were restricted by staff shortages particularly occupational therapy sessions. In addition to general boredom, they were also critical of the regimentation of life in psychiatric hospitals. A few participants however, found that structure provided relief from the responsibilities of day-to-day decisions.

While some said detention was "like going to hell", others referred positively to the experience of camaraderie among patients. Although some felt that being in hospital was the safest place when they fell ill, they were critical of poor conditions, being forced to live with seriously unwell people in cramped or mixed wards, enforced treatment, restrictions, and of inflexible and depersonalising regimes. Instead of being therapeutic, detention escalated problems:

I wasn't really getting any better...It wasn't anything to do with the Section, it was the ward. I just couldn't get better in there. I was just slowly really going off my head...."

(Female, F, Hospital CTO) 
Quality of inpatient experience was variable and linked to staff attitudes and behaviour. The experience was positive when the clinical team took the time to listen and be of benefit to patients, had a "good understanding of people"; were enthusiastic and responded flexibly to individual circumstances.

On the whole, participants reported poor planning and lack of involvement in hospital discharge, especially those leaving acute wards. Some however just wanted to leave hospital with minimal or no interference in their lives. For others, it was experienced as an abrupt end. Assumptions were made about the capacity of relatives to assume or resume care once the person left hospital, particularly when carers had been regular visitors, though they often did not receive advice or information about how to care for someone after a period of acute illness. In contrast, were some positive experiences including for one individual a phased return to the community, spending a few nights in his new community flat before moving out permanently.

\section{Community compulsion}

Around a third of participants reported being on community-based CTOs, having converted from hospital CTOs. Experience of this was at an early stage, and so hesitancy to offer definite views was understandable. What was common was that in practice community compulsion equated with "medication order", with the focus being on monitoring compliance. Service users expressed disappointment that they had not led to more holistic care packages. There were those who considered community compulsion a draconian measure: 
"Just basically restricting because I've got to keep to rules and regulations under it...I normally like to do things at my leisure...I don't like the emotional threat of 'you'll be re-called into hospital if you don't."

(Female, D\&G, Community CTO)

And those for whom it provided a comforting safety net:

"I think the psychiatrist would probably think 'well he's on a CTO, he's complaining of extreme depression and he can't look after himself currently', so they're more likely to say 'we'll bring him in'. It keeps me within the system..." (Male, F, Community CTO)

In principle, the notion of community treatment was a welcome development, especially in light of negative hospital-based experiences. Its potential lay in offering more individually tailored packages and in being a more "family friendly" option.

Ultimately, though not wholly antagonistic towards the idea, service users were unanimous that it was not preferable to, as one person put it, "being allowed to live a normal life" completely free of interference. More than anything, many wanted to be well and free of the worst symptoms, to be off powerful drugs with adverse effects, and to gain a sense of normality.

Improvements

Given that we found increased opportunity for participation did not of itself result in service users feeling their views had been listened to, it is noteworthy that "listening to patients more" continued to be an important theme:

"I think the patients ought to be listened to more often... and they're allowed a say because it is concerning them, and no bigwigs doing all the talking for us..."

(Female, D\&G, Community CTO)

This meant listening more to what service users said about the effects of powerful anti-psychotic drugs and considering alternative treatments. Several service users 
commented that what was on offer as treatment, both in hospital and in the community, needed to widen:

"Less of a reliance on drugs that's the major issue...Some kind of establishment of non drug therapy locally, which as I say I have experienced with good results...A lot of the nurses recognise that drug therapy is not the be all and end all and a lot of them have studied other therapies but don't get the chance to use them because of this top heavy dogmatic psychiatric approach that seems to be current across the country, right across the world." (Male, D\&G, Community CTO)

Related to consideration of alternatives was what one person highlighted in relation to the option of compulsory treatment in the community, which in her case had not been offered:

"With hindsight...I would have liked it if they said compulsory care at home rather than in the hospital. I didn't want to be in hospital and maybe I would have felt better, who knows, but it would have been nice if that was an option." (Female, F, Hospital CTO)

In some people's opinion, the quality, and consistency of ward staff could be improved. There was a demand for staff spending less time on paperwork and more with patients. As noted earlier, service users experienced vast differences between staff, even from one shift to another on the same ward, which as one person put it could be "a Jekyll and Hyde thing".

It was especially important to many service users to address the lack of occupation and boredom on the wards. Improving information about compulsion, including considering how and when this is best communicated, was vital. Some said the compulsory order had not been explained, or that they did not understand the effects 
of the drugs they had been prescribed, nor when the CTO would end. Having "someone to tell you what your rights are", and to explain the process, as well as "someone to turn to when you disagree with the whole system" was essential when people felt that no-one was representing their perspective.

\section{Discussion}

As a small-scale study in one part of the UK, there are limitations to generalising the findings to a wider population. Participants were self-selecting in response to a postal invitation. By design therefore, this may have excluded among others, service users whose first language was not English or people with learning disabilities, as well as those who felt unable to revisit what may have been a traumatic experience. Nonetheless, 49 people across Scotland participated in qualitative interviews ( $80 \%$ of these agreeing to be seen twice), sharing their personal experiences of compulsory treatment, often commenting that they felt valued by the research process. The interviews offer rare insights into the direct experience of compulsion in an under researched area with a 'hard to reach' population. Despite the data being collected in 2007-2008, the findings clearly resonate with key issues identified by other research and commentary.

Adopting a qualitative approach enabled a more nuanced understanding of the complexity of the experience of compulsory treatment (Hughes et al, 2009). A higher proportion of participants in our study felt that compulsion was justified in retrospect compared with those in other studies (Priebe et al, 2009), although they were less positive that compulsion had been necessary than participants in a study by 
O'Donoghue et al (2010). Other researchers (Priebe et al, 2010) highlight vast differences of opinion across different countries.

The MHCT Act had enhanced participation, though service users felt there was room for improvement, most particularly in relation to their involvement in care and treatment decisions. As found by Dawson et al (2009), the Named Person role was seen as empowering for some but not all service users, though it was crucial for those with few opportunities to access other forms of representation. While the very notion of involving people in their own detention might be incongruous, Advance Statements, involving collaborative planning between service users and professionals, arguably reduce power differentials, promoting self-determination, albeit under difficult circumstances, and potentially contributing to recovery (Hardcastle et al, 2007). The low uptake and scepticism evidenced in our study suggests the dominant psychiatric epistemology was little changed by new legislation. Atkinson (2010: 458) however, argues that their comparatively low use should not distract from the "brave attempt to put them at the core of mental health legislation".

The balance of power was invariably weighted in favour of professionals' judgement. Emphasis was on compliance with treatment regimes, rather than on building therapeutic relationships based upon concordance (Horne et al, 2005). Care planning was something professionals did about not with them, and care plans were not so much individually tailored, as formal records of deficits, professionally assessed needs, and allocated services. This trend runs counter to the national policy drive for increased choice and control in health and adult social care (Dept of 
Health, 2007; Scottish Government, 2010), as well as service user demands for alternative treatment frameworks that are 'whole-person based' and involve alternatives to drug therapies (Spandler \& Calton, 2009).

An assumption that community compulsory treatment is preferable, and that the experience in Scotland is positive (Cosh, 2009), was not entirely supported by our findings. Although its introduction was regarded by some service users as a positive innovation, the limits imposed on autonomy, choice and control were universally unpopular. Those with early experience of community CTOs reported feeling stigmatised by compulsion, regardless of setting, and regretted the missed opportunity for wider treatment alternatives and more recovery orientated approaches. Studies of the effectiveness of community compulsion in different countries remain inconclusive (Saks, 2003; Churchill, 2007); the need for further research into the outcomes and subjective experience of community compulsion is clear.

Even though legislative change had improved many aspects of the process, the direct experience of compulsion, especially of detention, remained unaffected. Addressing dissonance between policy aspirations, calls for progressive legislation and service frameworks, and individuals' experience of compulsion, will require more radical improvement in all parts of the system. The findings of this and other research suggest service users demand improvements in two key areas: the way mental health professionals relate to, and treat service users (Gilburt et al, 2008; Gault, 2009; Hughes et al, 2009); and secondly, alternative forms of treatment and a 
variety of service options (Hughes et al, 2009; Spandler \& Calton, 2009). In this study, service users also indicated that compulsory treatment would be improved by better access to advocacy to ensure more people fully understand their rights and participate in decisions about their care and treatment under the MHCT Act, bringing to mind the system of Independent Mental Health Advocacy implemented south of the border (Newbigging et al, 2012). 


\section{References}

Atkinson, J. (2010), Advance statements: the view from Scotland. Commentary on Advance Statements in Adult Mental Health. Advances in psychiatric treatment. 16. 456-458.

Atkinson, J., Reilly, J., Garner, H. C., \& Patterson, C. (2005) Review of Literature Relating to Mental Health Legislation. Edinburgh: Scottish Executive Social Research.

Canvin, K., Bartlett, A., \& Pinfold, V. (2002), A 'bittersweet pill to swallow': learning from mental health service users' responses to compulsory community care in England. Health and Social Care in the Community, 10 (5), 361-369.

Churchill, R. (2007) “International experiences of using community treatment orders", King's College London: Institute of Psychiatry, University of London.

Coffey, A. \& Atkinson, P. (1996) Making Sense of Qualitative Data, London: Sage Publications.

Cosh, J. (2009), Northern exposure, Mental Health Today. March, 16-18.

Dawson, A., Ferguson, I., Mackay, K., \& Maxwell, M. (2009), An Assessment of the Operation of the Named Person Role and its Interaction with Other Forms of Patient Representation. Edinburgh: Scottish Government Social Research. 
Department of Health, (2007), Putting People First: a shared Vision and Commitment to the Transformation of Adult Social Care. London: DH.

Fowler, G (2011), Increase in Psychiatric Compulsion in the UK, Asylum, Winter 2011, Vol 18, No 4, 8.

Gault, I. (2009), Service-user and carer perspectives on compliance and compulsory treatment in community mental health services. Health and Social care in the Community. 17, 5, 504-513.

Gilburt, H., Rose, D., \& Slade, M. (2008), The importance of relationships in mental health care: A qualitative study of service users' experiences of psychiatric hospital admission in the UK. BMC Health Services Research. 8: 92.

doi: $10.1186 / 1472-6963-8-92$

Glasby, J., \& Lester, H. (2005), On the Inside: A Narrative Review of Mental Health Inpatient Services. British Journal of Social Work. 35. 863-879.

Grant, S.E. (2004) National Mental Health Services Assessment: Towards implementation of the Mental Health (Care and Treatment) (Scotland) Act 2003, Edinburgh: Scottish Executive. 
Gould, M. 2011, Mental health patients complain of 'zombification'. The Guardian, Tuesday 15 March 2011. Access online May 2012:

http://www.guardian.co.uk/society/2011/mar/15/mental-health-patients-forceddetention

Hardcastle, M., Kennard, D., Grandison, S., et al (2007) Experiences of Mental Health In-Patient Care: Narratives from Services Users, Carers and Professionals. London: Routledge.

Horne, R., Weinman, J., Barber, N., et al (2005), Concordance, adherence and compliance in medicine taking. Report for the National Co-ordinating Centre for NHS Service Delivery and Organisational R\&D. (NCCSDO).

Hughes, R., Hayward, M., \& Finlay, W. M. L. (2009), Patients' perception of the impact of involuntary inpatient care on self, relationships and recovery. Journal of Mental Health, 18, 2, 152-160.

ISD Scotland (2011), Mental Health (Psychiatric) Hospital Activity Statistics year ending 31 March 2011, Edinburgh: ISD/NHS National Services Scotland http://www.isdscotland.org/Health-Topics/Mental-Health/Publications

Johansson, I. M., \& Lundman, B. (2002), Patients' experience of involuntary psychiatric care: good opportunities and great losses. Journal of Psychiatric and Mental Health Nursing, 9, 639-647. 
Jones, I., Ahmed, N., Catty, J., et al (2009), Illness careers and continuity of care in mental health services: A qualitative study of service users and carers. Social Science \& Medicine, 69, 632-639.

Lorem, G., F. (2008), Making sense of stories: the use of patient narratives within mental health care research. Nursing Philosophy, 9, 62-71.

Miles, M. B., \& Huberman, M. (1994), Qualitative Data Analysis: An Expanded Sourcebook. $2^{\text {nd }}$ Edition. California: Sage Publications Inc.

Millan Committee, (2001), New Directions. Report on the Review of the Mental Health (Scotland) Act 1984. Edinburgh: Scottish Executive.

Newbigging, K., Ridley, J., McKeown, M., et al (2012), The Right to Be Heard: Review of Independent Mental Health Advocate (IMHA) Services in England. Preston: UCLAN Print Shop.

O'Donoghue, B., Lyn, J., Hill, M et al (2010), Involuntary admission from the patients' perspective. Soc. Psychiat Epidemiol. 45: 631-638.

doi: $10.1007 / \mathrm{s} 00127-009-0104-7$

Patrick, H. (2006) Mental Health, Incapacity and the Law in Scotland. Edinburgh: Tottel Publishing. 
Pilgrim, D. (2007), New "mental health" legislation for England and Wales: some aspects of consensus and conflict. Journal of Social Policy, Vol 36, No 1, 1-17.

Priebe, S., Katsakou, C., Glockner, M., et al (2009), Patients' views of involuntary hospital admission after 1 and 3 months: prospective study in 11 European countries. British Journal of Psychiatry. 196, 3, 179-185.

Priebe, S., Katsakou, C., Amos, T., et al (2009), Patients' views and readmissions 1 year after involuntary hospitalisation. British Journal of Psychiatry, 194, 49-54, doi: 10.1192/bjp.bp.108.052266.

Ridley, J., Hunter, S., \& Rosengard, A., (2010), Partners in care? Views and experiences of carers from a cohort study of the early implementation of the Mental Health (Care \& Treatment) (Scotland) Act 2003. Health and Social Care in the Community, 18, 5, 474-482.

Ridley, J., Rosengard, A., Hunter, S., et al (2009), Experiences of the early implementation of the Mental Health (Care \& Treatment) (Scotland) Act 2003: A cohort study. Scottish Government. (Web only) www.scotland.gov.uk/Publications/2009/05/061558131/2

Rose, D. (2004), Telling Different Stories: User Involvement in Mental Health Research, in Research. Policy and Practice, 22, 2, 1-8. 
Rosengard, A. \& Laing, I. (2001) User Consultation on the Millan Report. Edinburgh: Scottish Executive CRU.

Rushmer, R. \& Hallam, A. (2004), Mental Health Law in Scotland: Mental Health Law Research Programme. Analysis of Responses to Consultations. Edinburgh: Scottish Executive.

Saks, E.R. (2003), Refusing Care: Forced Treatment and the Rights of the Mentally ill., Chicago: University of Chicago Press.

Scottish Recovery Network (2007) "Routes to Recovery: Collected wisdom from the SRN Narrative Research Project”. Glasgow SRN. www.Scottishrecovery.net

Spandler, H., \& Calton, T. (2009), Psychosis and Human Rights: Conflicts in Mental Health Policy and Practice. Social Policy \& Society, 8, 2, 245-256.

Szasz, T. (1974), The Myth of Mental Illness: Foundations of a Theory of Personal Conduct. Revised Edition. New York: Harper Collins.

Szmukler, G. (2009), Service users in research and a 'well ordered science'. Journal of Mental Health, 18, 2, 87-90.

Temple, B. (1998) A fair trial? Judging quality in qualitative research. International Journal of Social Research Methodology, 1, 3, 205-215. 
Turner, M. \& Beresford, P. (2005), User Controlled Research. Its Meanings and potential. Report Summary. Shaping our Lives and the Centre for Citizen Participation. Hants: INVOLVE. 
Table 1: Number of responses and interviews carried out with service users in the four research sites

\begin{tabular}{|l|c|c|c|c|c|}
\hline Description & Dumfries \& & Fife & Glasgow & State & TOTAL \\
& Galloway & (F) & (G) & & Hospital \\
(SH) & & \\
\hline All Respondents & 12 & 17 & 26 & 8 & 63 \\
\hline Withdrew & 1 & - & 2 & - & 3 \\
\hline Nominated & - & 2 & 2 & 3 & 7 \\
professional did not & & & & & 4 \\
\hline Consent & 1 & 1 & 2 & - & 49 \\
\hline Interviewed at Stage 1 & 10 & 14 & 20 & 5 & \\
\hline Interviewed at Stage 2 & 7 & 10 & 17 & 5 & \\
\hline
\end{tabular}


Table 2: Summary characteristics of the group of service users interviewed

\begin{tabular}{|l|l|}
\hline Characteristic of the group (=49) & Statistic \\
\hline Sex - percent & $67 \% \mathrm{M:} \mathrm{33 \%} \mathrm{F}$ \\
Youngest participant & 40.5 years \\
Oldest participant & 21 years \\
Black or minority ethnic group, including asylum seekers & 63 years \\
Learning disabilities and/or autistic spectrum condition (ASC & $8 \%$ \\
Living situation & $8 \%$ \\
Living in own home by self or with others & 1 \\
Detained in psychiatric hospital (including IPCUs) & 24 \\
Supported housing & 3 \\
Residential or nursing homes & 2 \\
Parental home & 15 \\
\hline
\end{tabular}


Table 3: Most recent self-reported experience of compulsory measures at Stage 1 interviews by research site

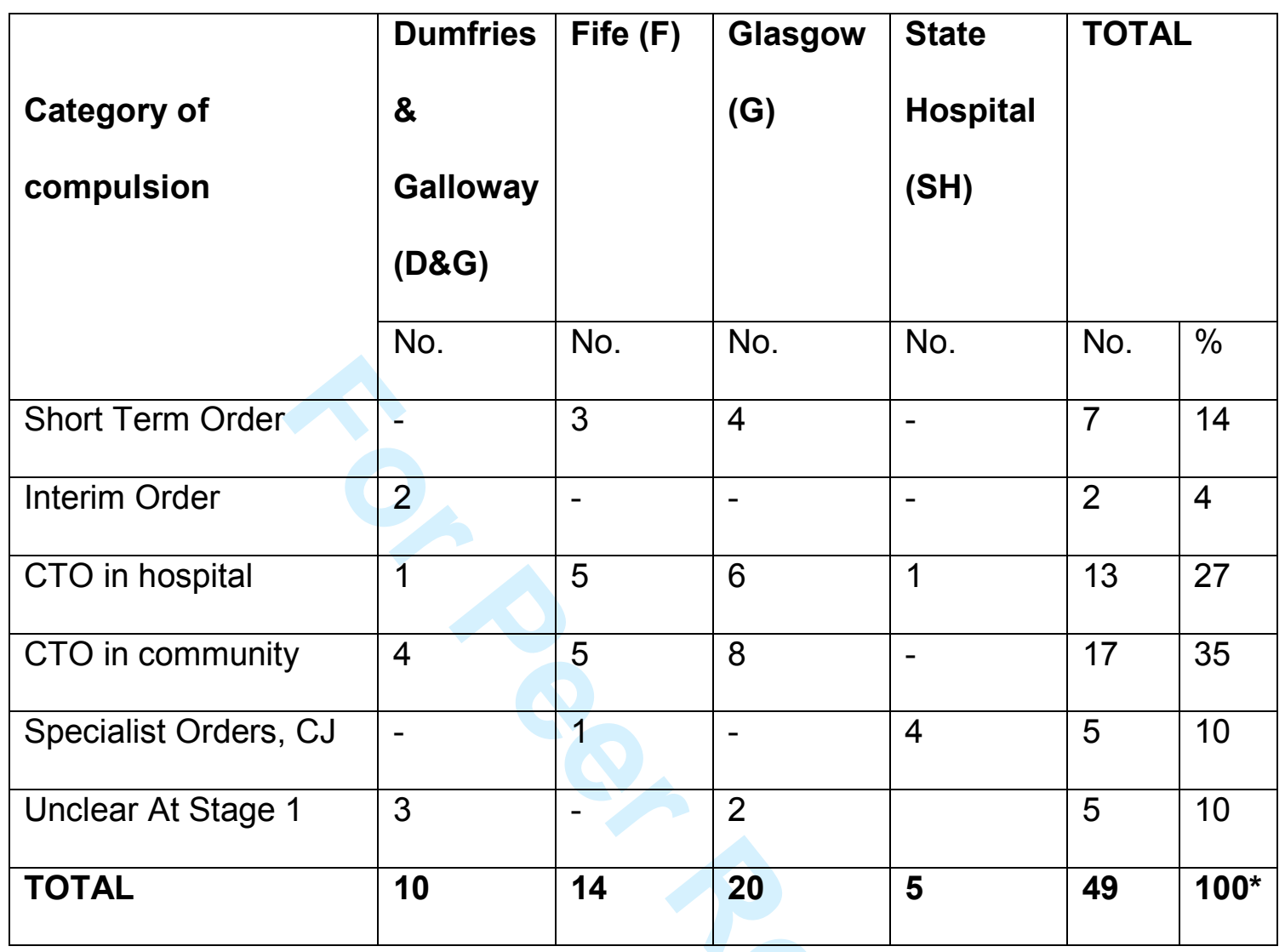




\section{Box 1: Summary Stage 1 interview questions}

- Thinking about the time before you were placed under compulsory measures, can you tell us what led up to that?

- Do you know about Advance Statements, and do you have one?

- If you've attended a Mental Health Tribunal, what was it like? If you didn't attend, why did you decide not to attend?

- Do you have a Named Person? Did you choose them? If you do, did they attend your Tribunal?

- What has it been like being detained in hospital under compulsory treatment?

- How well has your care and treatment under compulsory care met your needs?

- (If on community treatment order) What has being on a CTO been like for you?

- Can you suggest up to three things that would improve yours or other people's experience of compulsory treatment?

- What might improve support in the community? 


\section{Box 2: Summary Stage 2 questions and checks}

- How did you feel about being interviewed by us the last time?

- Updating information from Stage 1 interview - living situation; whether the compulsory order still applies or when this ended;

- If attended a Tribunal since last interview, tell us what happened and how it went

- Last time, you told us you did/did not know about Advance Statements. Have your views about Advance Statements changed in any way?

- How has having a Named Person worked for you? Have you changed or are you about to change your Named Person for any reason?

- Go over key point from stage 1 interview about care and treatment - is it meeting your needs?

- Looking back, do you think compulsory care was the right thing for you or not? 